\title{
Photocatalytic Degradation of Organics in Municipal Treated Wastewater in a Re-Circulation Reactor
}

\author{
Anna Jesil Cheriyan ${ }^{1}$, Jyoti Prakash Sarkar ${ }^{2}$, Feroz Sheik ${ }^{1}$, Mahad Said Baawain ${ }^{3}$ \\ ${ }^{1}$ Mechanical \& Industrial Engineering Department, Caledonian College of Engineering, Al Khoudh, Muscat, Sultanate of Oman; \\ ${ }^{2}$ National Institute of Technology, Durgapur, India; ${ }^{3}$ Sultan Qaboos University, Al Khoudh, Muscat, Sultanate of Oman. \\ Email: annajesil@gmail.com
}

Received September $17^{\text {th }}, 2013$; revised October $18^{\text {th }}, 2013$; accepted November $15^{\text {th }}, 2013$

Copyright (C) 2013 Anna Jesil Cheriyan et al. This is an open access article distributed under the Creative Commons Attribution License, which permits unrestricted use, distribution, and reproduction in any medium, provided the original work is properly cited. In accordance of the Creative Commons Attribution License all Copyrights (C) 2013 are reserved for SCIRP and the owner of the intellectual property Anna Jesil Cheriyan et al. All Copyright (C) 2013 are guarded by law and by SCIRP as a guardian.

\begin{abstract}
In this paper, an experimental investigation on the effect of parameters namely concentration, solar radiation intensity and exposure time on the photo oxidation of pollutants in secondary treated municipal wastewater has been presented. $\mathrm{TiO}_{2}$ was used as the photo catalyst and the experiments were carried out in the month of February 2012 in Oman. The reactor was a glass tube constructed with the provision of adding a reflector. The results showed that photo catalytic treatment is very effective for dilute solutions and the presence of reflector enhances the photo degradation. The reduction in Chemical Oxygen Demand (COD) obtained at the experimental conditions of $0.007 \mathrm{~m}^{3} / \mathrm{hr}$ flow rate, $15^{\circ}$ inclination angle and $1 \mathrm{~g} \cdot \mathrm{L}^{-1} \mathrm{TiO}_{2}$ dosage was $18 \%$. The presence of the reflector increased the degradation to $25 \%$ at the above experimental conditions.
\end{abstract}

Keywords: COD; Municipal Wastewater; Photo Catalyst; Solar Radiation

\section{Introduction}

In this experimental study, the photo catalyst was used in suspension form as slurry that was re-circulated through the batch reactor at the optimized conditions. The optimized conditions were obtained from previous experiments performed using immobilized catalyst. The flow rate was fixed at $0.007 \mathrm{~m}^{3} / \mathrm{hr}$ and the angle of inclination was fixed at $15^{\circ}$. Different concentrations of the municipal waste water at $0 \%, 25 \%$ and $50 \%$ dilutions were attempted.

Catalyst was used in the suspended form to utilize the high surface area of the catalyst that will be available for illumination [1]. A catalyst loading of $1 \mathrm{gm} \cdot \mathrm{L}^{-1}$, based on literature review [2] was employed for the same. The effect of dilution, addition of reflector and exposure time was studied and the performance was assessed by measurement of COD, anions and total coliforms inactivation.

$\mathrm{TiO}_{2}$ was the photo catalyst used as it is less expensive, available commercially, non-toxic and photo-chemicallystable. Researchers [3-5] have demonstrated $\mathrm{TiO}_{2}$ to be an effective catalyst that is quite non-selective as the reaction is based on the free radical mechanism.
The reflector that was used for the experiment was a Compound Parabolic trough reflector as shown in Figure 1, made of electro polished Aluminum sheet. It was designed in such a way that the co-focal point was made as the co-focal line of the reactor pipe, where there will be the maximum of concentrated solar energy delivered and transferred to the energy absorber tube making it more efficient. Researchers [6-8] have summarized the advantages which is mainly the utilization of the diffused radiation in addition to concentration of solar radiation. They have shown to be exhibiting high optical and quantum efficiency [9]. It is observed that [6-9] using this type of collector, the output energy of a solar energy capture tube can be increased by a factor of $4-6$ times using a stationary solar collector. Researcher [10] reviewed the application of compound parabolic collector for its application in waste water treatment as it is quite advantageous.

\section{Materials and Method}

Mean composition of the municipal wastewater, collected from Al Khoudh municipal wastewater plant has 


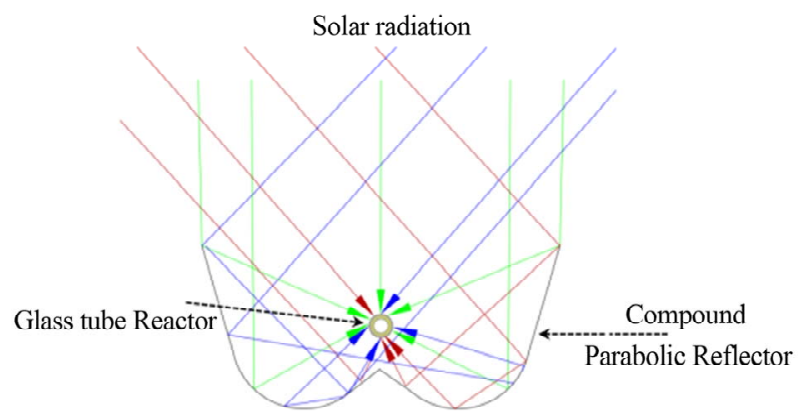

Figure 1. Schematic diagram of the reflector.

been given in Table 1. The samples were transferred and stored immediately under refrigerated condition in the lab.

\section{Photocatlytic Reactor}

The schematic of the reactor used for the experiments has been shown in Figure 2. The glass tube used as reactor was of length approximately $50 \mathrm{~cm}$ and was having inner diameter of $8 \mathrm{~mm}$ and outer diameter $10 \mathrm{~mm}$. The total volume handled was 5 litres. A peristaltic pump was used for re-circulation.

\section{Reagents}

$\mathrm{TiO}_{2}$ (Merck) which has $70 \%$ Anastase was used in suspension mode. The Chemical Oxygen Demand was determined by the Dichromate Reflux method, using Potassium dichromate, Sulphuric acid/Silver Sulphate solution, Mercuric Sulphate, Ferrous Ammonium sulphate and Ferrion indicator, all being reagent grade.

\section{Photocatalytic Experiments}

The experiments were carried out under solar radiation in the Sultan Qaboos University campus. The radiation was measured by a radiometer (model Sunaay). The average solar radiation intensity varied from $46 \mathrm{~mW} / \mathrm{cm}^{2}$ to 75 $\mathrm{mW} / \mathrm{cm}^{2}$ from 08:30 AM to 02:30 PM in the month of July-August and from $8 \mathrm{~mW} / \mathrm{cm}^{2}$ to $68 \mathrm{~mW} / \mathrm{cm}^{2}$ from 08:30 AM to $02: 30$ PM in the month of January-February in Oman for the year 2011-2012. A 5-litre sample of wastewater was used for the experiments.

The first set of experiments was performed without any dilution of the waste water. $1 \mathrm{~g} \cdot \mathrm{L}^{-1}$ of $\mathrm{TiO}_{2}$ was dissolved in the waste water. After allowing it to settle down, the effluent was transferred for the experimental use. The effluent was re-circulated through the reactor system for a period of 5 hours starting from 09:30 AM. The sample was taken after every 1 hour for parameter analysis. The second and third sets of experiments were performed with $25 \%$ dilution and $50 \%$ dilution respectively.

The aqueous solution was re-circulated for 1 hour un-

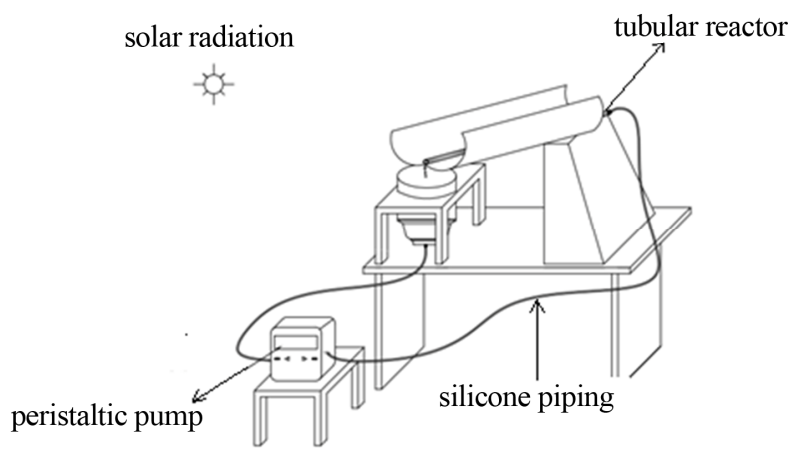

Figure 2. Schematic of the experimental set up used.

Table 1. Secondary treated municipal waste water characteristics.

\begin{tabular}{cc}
\hline Parameter (unit) & Concentration \\
\hline $\mathrm{COD} \mathrm{mg} \cdot \mathrm{L}^{-1}$ & 62 \\
$\mathrm{pH}$ & 7.4 \\
Fluoride $\mathrm{mg} \cdot \mathrm{L}^{-1}$ & 0.52 \\
Chloride $\mathrm{mg} \cdot \mathrm{L}^{-1}$ & 153 \\
Nitrate $\mathrm{mg} \cdot \mathrm{L}^{-1}$ & 1.17 \\
Nitrite $\mathrm{mg} \cdot \mathrm{L}^{-1}$ & 0.27 \\
Bromide $\mathrm{mg} \cdot \mathrm{L}^{-1}$ & 0.13 \\
Sulphate $\mathrm{mg} \cdot \mathrm{L}^{-1}$ & 102 \\
Phosphate $\mathrm{mg} \cdot \mathrm{L}^{-1}$ & 5.0 \\
Bicarbonate $\mathrm{mg} \cdot \mathrm{L}^{-1}$ & 154 \\
Total Coliforms $\mathrm{MPN}$ & Max \\
\hline
\end{tabular}

der dark conditions for equilibration to be achieved. Samples were withdrawn after every 15 minutes and analyzed for COD and other parameters. The system was then exposed to solar radiation for a period of 5 hours. The samples were withdrawn at the start of the irradiation experiments at a fixed time interval of 1 hour.

\section{Evaluation of Solar UV Radiation}

A mathematical model that has been applied by many researchers $[3,11]$ was used to find the effect of solar radiation on the photo catalytic treatment of the effluent. The solar radiation intensity depends on the weather condition, month of the year and time of the day. The model uses relationship between experimental time $\left(t_{n}\right.$, hr), plant volume $\left(V_{t}, 1\right)$, collector surface area $\left(A_{r}, \mathrm{~m}^{2}\right)$ and the radiant power $\left(U V_{G, n}, \mathrm{~mW} / \mathrm{cm}^{2}\right)$ measured by the radiometer.

$$
Q_{U V, n}=Q_{U V, n-1}+\Delta t U V_{G, n}\left(\frac{A_{r}}{V_{t}}\right) J l^{-1}
$$




$$
\Delta t=t_{n}-t_{n-1}
$$

Table 2 shows the average accumulated radiation energy from 08:30 AM to 02:30 PM in the month of January-February 2012. Figure 3 shows the variation in UV intensity during the day.

\section{Result and Discussion}

The results from the experiment have been shown in Figures 4-7. The variations in COD have been shown as a function of exposure time and accumulated energy at different dilutions. For $0 \%$ dilution the degradation in COD was found to be $14 \%$ at the end of $5 \mathrm{hr}$ exposure to solar radiation. This increased to $16 \%$ and $18 \%$ for $25 \%$ and $50 \%$ dilutions respectively. However, in the presence of a reflector, the reduction in COD was $25 \%$ for $50 \%$ dilution of municipal wastewater.

The redox environment created due to the presence of $\mathrm{TiO}_{2}$ in catalyst is very effective for the degradation of organics and removal of pollutants. At high concentrations of the catalyst, reduction in efficiency will be there due to screening effect and solution opacity. Hence the effectiveness was more observed for $50 \%$ dilution of the waste water.

Table 2. Accumulated radiant energy for the month of February 2012.

\begin{tabular}{|c|c|c|c|}
\hline Month/year & & January-February 2 & 012 \\
\hline \multirow[b]{2}{*}{ Time } & \multirow{2}{*}{$\begin{array}{c}\mathrm{UV} \\
\left(\mathrm{mW} / \mathrm{cm}^{2}\right)\end{array}$} & Without reflector & With reflector \\
\hline & & $\begin{array}{l}\text { Q accumulated } \\
\mathrm{kJ} \cdot 1^{-1}\end{array}$ & $\begin{array}{l}\text { Q accumulated } \\
\mathrm{kJ} \cdot 1^{-1}\end{array}$ \\
\hline 07:30 - 08:30 AM & 8 & 0 & 0 \\
\hline 08:30 - 09:30 AM & 25 & 1 & 2 \\
\hline 09:30 - 10:30 AM & 44 & 3 & 6 \\
\hline $10: 30$ - 11:30 AM & 58 & 6 & 11 \\
\hline $11: 30-12: 30 \mathrm{PM}$ & 67 & 9 & 17 \\
\hline $12: 30-01: 30 \mathrm{PM}$ & 70 & 12 & 23 \\
\hline 01:30 - 02:30 PM & 68 & 15 & 29 \\
\hline
\end{tabular}

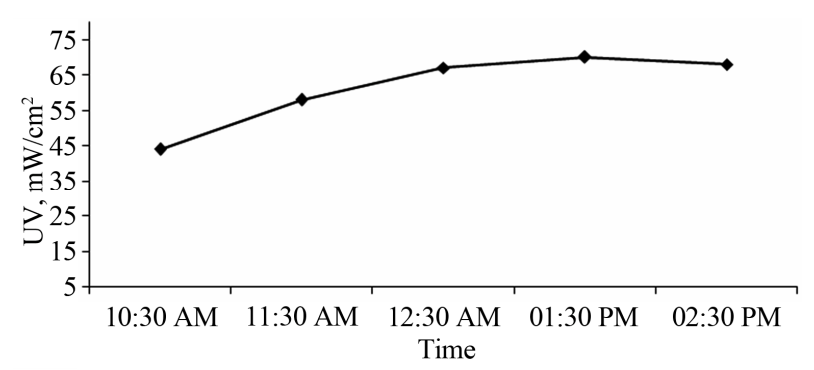

Figure 3. Variation in UV intensity during the February in Oman, year 2012.

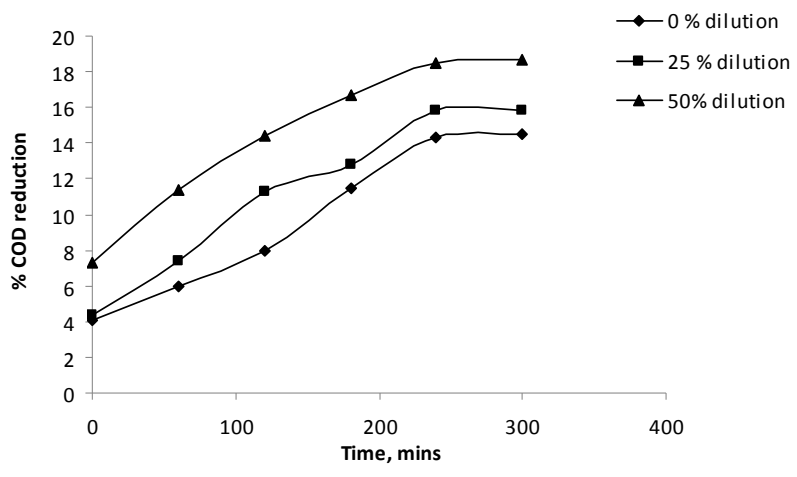

Figure 4. Effect of dilution of the waste water on the \% reduction in COD using catalyst in suspension at $1 \mathrm{~g} \cdot \mathrm{l}^{-1}$, with angle of inclination $15^{\circ}$ and $0.007 \mathrm{~m}^{3} / \mathrm{hr}$ flow rate.

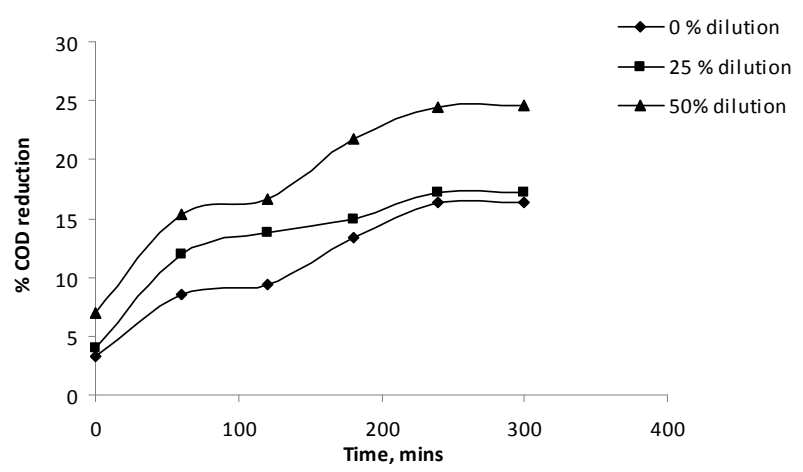

Figure 5. Effect of dilution of the waste water in COD decrease in the presence of a reflector in COD with reflector, angle $15^{\circ}$, with $\mathrm{TiO}_{2}$ at $1 \mathrm{~g} \cdot \mathrm{I}^{-1}$ in suspension mode.

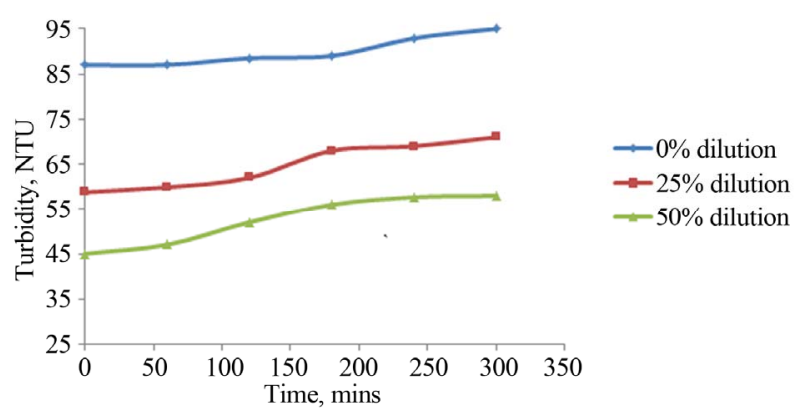

Figure 6. Variation in turbidity without reflector using catalyst as suspension at different waste water dilutions, with angle of inclination $15^{\circ}$ and $0.007 \mathrm{~m}^{3} / \mathrm{hr}$ flow rate as a function of experimental time.

The increase in exposure time leads to an overall increase in accumulation energy and hence the increase in degradation with increase in exposure time can be observed.

The effect of photo catalysis on the concentration of anions and total Coliforms also followed the same trend. The anions reduction is due to the reduction that takes place on account of the electrons generated during the photo catalysis reaction.

The variation in turbidity of the effluent after the 


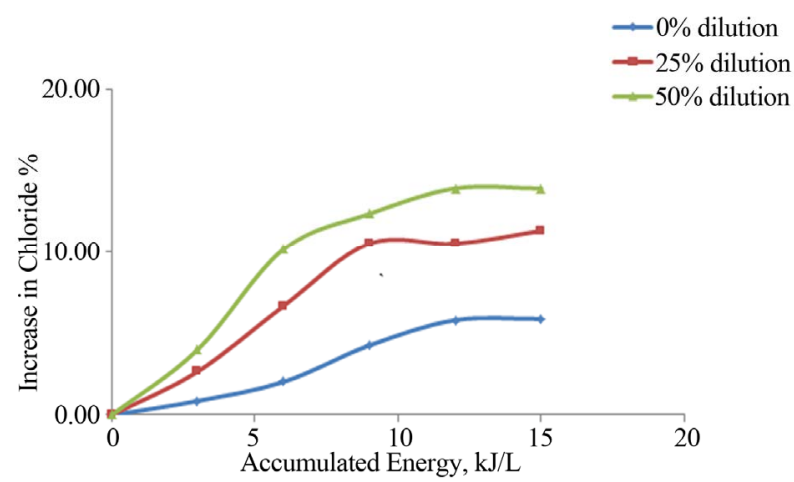

Figure 7. Increase in chloride without reflector, angle $15^{\circ}$, $\mathrm{TiO}_{2}$ at $1 \mathrm{~g} \cdot l^{-1}$ suspension at different waste water dilutions as a function of accumulated energy.

photocatalytic treatment has been depicted in Figure 6. The slight increase in turbidity is attributed to the nano sized $\mathrm{TiO}_{2}$ particles that could not be removed by centrifuging.

The increase in Chloride ions has been shown in Figure 7. The degradation of the pollutants is due to photocatalysisleaded to increase in the anions. At 50\% dilution, the photocatalytic efficiency was much more, observed as $14 \%$ increase in Chloride.

The surface area of the catalyst powder was measured with Acorn area surface area analyzer (XiGonano tools), and the average area was $27 \mathrm{~m}^{2} / \mathrm{g}$.

Based on the experimental investigations carried out, it can be deduced that the application of photocatalysis method for the secondary treated water may be a viable option, given that the world is beginning to experience an acute fresh water shortage. There are further advantages of application of photocatalysis in the tertiary treatment stage, that includes utilisation of solar energy, avoiding formation of hazardous by products.

\section{Acknowledgements}

This work was supported in part by The Research Council Oman under grant TRC105789.

\section{REFERENCES}

[1] M. Cathy, K. J. Peter, A. Morgan, M. P. Pat and M. Abdulrahman, "Development of a Slurry Continuous Flow
Reactor for Photo Catalytic Treatment of Industrial Wastewater," Journal of Photochemistry and Photobioloigy: A Chemistry, Vol. 211, No. 1, 2010, pp. 42-46.

[2] R. L. Prieto, S. Miralles-Cuevas, J. Oller, F. I. Pilar, A. Aguera, J. Blanco and J. Malato, "Optimisation of Mild Solar $\mathrm{TiO}_{2}$ Photocatalysis as a Tertiary Treatment for Municipal Wastewater Treatment Plants," Applied Catalysis B: Environmental, Vol. 128, A Special Issue Dedicated to Jean-Marie Herrmann, 2012, pp. 119-125.

[3] D. Robert, A. Piscopo and J. V. Weber, "Selective Photo Degradation of Organopollutant Mixtures in Water," Solar Energy, Vol. 77, No. 5, 2004, pp. 553-558.

[4] A. Sobczynski and A. Dobasz, "Water Purification by Photocatalysis on Semiconductors," Polish Journal of Environmental Studies, Vol. 10, No. 4, 2001, pp. 195-205.

[5] M. Kositzi, I. Poulios, S. Malato, J. Caceres and A. Campos, "Solar Photocatalytic Treatment of Municipal Wastewater," Water Research, Vol. 38, No. 5, 2004, pp. 1147 1154.

[6] V. Sarria, S. Kenfack, O. Guillod and C. Pulgarin, "AnInnovative Coupled Solar Biological System at Field Pilot Scale for the Treatment of Bio Recalcitrant Pollutants," Journal of Photochemistry and Photobiology. A: Chemistry, Vol. 159, No. 1, 2003, pp. 88-99.

[7] S. Malato, J. Blanes, A. Vidal, D. Alarcon, M. I. Maldonado, J. Caceres and W. Gernjak, "Applied Studies in Solar Photo Catalytic Detoxification: An Overview," Solar Energy, Vol. 75, No. 4, 2003, pp. 329-336.

[8] J. I. Ajona and A. Vidal, "The Use of CPC Collection for Detoxification of Contaminated Water; Design, Construction and Preliminary Results," Solar Energy, Vol. 68, No. 1, 2000, pp. 109-120.

[9] S. Malato, J. Blanco, D. C. Alarcon, M. I. Maldonado, F. I. Ibanez and W. Gernjak, "Photocatalytic Decontamination and Disinfection of Water with Solar Collectors," Catalysis Today, Vol. 122, No. 1-2, 2007, pp. 137-149.

[10] M. Tanveer and T. G. Guyer, "Solar Assisted Photo Degradation of Wastewater by Compound Parabolic Collectors: Review of Operational and Design Paarameters," Renewable and Sustainable Energy Reviews, Vol. 24, 2013, pp. 534-543.

http://dx.doi.org/10.1016/j.rser.2013.03.053

[11] C. Sichel, J. Blanco, S. Malato and F. I. Pilar, "Effects of Experimental Conditions on E. coli Survival during Solar Photocatalytic Disinfection," Journal ofPhotochemistry and Photobiology A: Chemistry, Vol. 189, No. 2-3, 2007, pp. 239-246. 